\title{
The Stigma Turbine: A Theoretical Framework for Conceptualizing and Contextualizing Marketplace Stigma
}

\author{
Ann M. Mirabito, Cele C. Otnes, Elizabeth Crosby, David B. \\ Wooten, Jane E. Machin, Chris Pullig, Natalie Ross Adkins, \\ Susan Dunnett, Kathy Hamilton, Kevin D. Thomas, Marie A. \\ Yeh, Cassandra Davis, Johanna F. Gollnhofer, Aditi Grover, \\ Jess Matias, Natalie A. Mitchell, Edna G. Ndichu, Nada \\ Sayarh, and Sunaina Velagaleti
}

\begin{abstract}
Stigmas, or discredited personal attributes, emanate from social perceptions of physical characteristics, aspects of character, and "tribal" associations (e.g., race; Goffman 1963). Extant research has emphasized the perspective of the stigma target, with some scholars exploring how social institutions shape stigma. Yet the ways stakeholders within the sociocommercial sphere create, perpetuate, or resist stigma remain overlooked. The authors introduce and define marketplace stigma as the labeling, stereotyping, and devaluation by and of commercial stakeholders (consumers, companies and their employees, stockholders, and institutions) and their offerings (products, services, and experiences). The authors offer the Stigma Turbine as a unifying conceptual framework that locates marketplace stigma within the broader sociocultural context and illuminates its relationship to forces that exacerbate or blunt stigma. In unpacking the Stigma Turbine, the authors reveal the critical role that market stakeholders can play in (de)stigmatization, explore implications for marketing practice and public policy, and offer a research agenda to further understanding of marketplace stigma and stakeholder welfare.
\end{abstract}

Keywords: stigma, discrimination, marketplace, stereotype, intersectionality

S tigmas arise from personal attributes others perceive as "deeply discrediting" (Goffman 1963, p. 15). Depending on the dominant cultural values in particular historical periods, such attributes can include, to use Goffman's (1963) terminology, "physical deformities" (e.g., gender, age, disabilities), "character blemishes" (e.g., sexual orientation, mental disorders, extreme spending behaviors), and "tribal" associations (e.g., race, ethnicity,

Ann M. Mirabito is Associate Professor of Marketing (e-mail: Ann_Mirabito@Baylor.edu), and Chris Pullig is Professor of Marketing (e-mail: Chris_Pullig@baylor.edu), Baylor University. Cele C. Otnes is Investors in Business Education Professor of Marketing, University of Illinois at Urbana-Champaign (e-mail: cotnes@illinois.edu). Elizabeth Crosby is Assistant Professor of Marketing, University of Wisconsin-La Crosse (e-mail: ecrosby@uwlax.edu). David B. Wooten is Alfred L. Edwards Collegiate Professor of Marketing, University of Michigan (e-mail: dbwooten@umich.edu). Jane E. Machin is Assistant Professor of Marketing, Radford University (e-mail: jmachin@radford.edu). Natalie Ross Adkins is Associate Professor of Marketing, Drake University (e-mail: natalie.adkins@drake.edu). Susan Dunnett is Lecturer in Marketing, University of Edinburgh (e-mail: Susan. Dunnett@ed.ac.uk). Kathy Hamilton is Reader in Marketing, University of Strathclyde (e-mail: kathy.hamilton@strath.ac.uk). Kevin D. Thomas is Assistant Professor (e-mail: kevin.thomas@utexas.edu), and Jess Matias is a doctoral candidate in advertising (e-mail: jessmatias@utexas.edu), University of Texas at Austin. Marie A. Yeh is Assistant Professor, Loyola University Maryland (e-mail: mayeh@loyola.edu). Cassandra Davis is a doctoral candidate in marketing, University of Arkansas (e-mail: cdavis@walton.uark.edu). Johanna F. Gollnhofer is Research Associate, University of St. Gallen (e-mail: johanna.gollnhofer@unisg.ch). Aditi Grover is Clinical Assistant Professor of Marketing, Oklahoma State University (e-mail: aditi.grover@ okstate.edu). Natalie A. Mitchell is Visiting Assistant Professor of Marketing, Tulane University (e-mail: nmitche1@tulane.edu). Edna G. Ndichu is a doctoral candidate in management and marketing, University of Wyoming (e-mail: endichu@uwyo.edu). Nada Sayarh is a doctoral candidate in marketing, University of Geneva (e-mail: essaigh@hotmail.com). Sunaina Velagaleti is a doctoral candidate in marketing, University of Wisconsin-Madison (e-mail: velagaleti@wisc.edu). The authors thank Julie A. Ruth for helpful comments on an earlier version of the manuscript, as well as the JPPM review team for their constructive comments. Brennan Davis served as associate editor for this article. 
nationality). The literature has explored how marginalized people and social groups cope with negative consequences of stigma, such as diminished self-esteem and depression (Goffman 1963; Keene, Cowan, and Baker 2015), damaged mental or physical health (Yang et al. 2007), and lessened opportunities for economic and social advancement (Van Laar et al. 2010). Less understood is the complex relationship between stigma and the marketplace. Yet as Table 1 illustrates, marketplace stakeholders often create, perpetuate, and resist stigma.

We define the underexplored concept of marketplace stigma as the labeling, stereotyping, and devaluation by and of commercial stakeholders (consumers, companies and their employees, stockholders, and institutions) and their offerings (products, services, and experiences). This definition captures the two fundamental components of stigmatizationrecognizing a difference from a perceived norm, followed by devaluing the deviating entity (Dovidio, Major, and Crocker 2000). Extant research has explored marketplace stigma as it pertains to products and service encounters (Adkins and Ozanne 2005; Crockett, Grier, and Williams 2003), consumer coping strategies (Ho and O'Donohoe 2014; Nguyen, Chen, and Mukherjee 2014), and the impact of stereotypes on consumer behavior (Campbell and Mohr 2011; Matta and Folkes 2005; Yeh, Jewell, and Hu 2013). Yet the literature on marketplace stigma is fragmented, and no unifying conceptual framework situates the phenomenon within broader sociocultural discourses on (de)stigmatization or shows how the marketplace can be a wellspring from which (de)stigmatization can emanate. Understanding marketplace stigma is crucial because, across the globe, consumers' identity projects are increasingly tied to acquiring goods, services, and experiences that convey social status and conformity to aspirational social norms (Arnould and Thompson 2005). Thus, marketplace stigma can wield painful consequences for those lacking the resources to own or display culturally valorized goods, services, and experiences-pointing to the need for research and public policy agendas dedicated to improving consumer welfare and social justice through destigmatization.

To fully investigate the processes and contexts associated with marketplace stigma, we offer the Stigma Turbine (ST; see Figure 1) as a unifying conceptual framework that appropriately locates it within the exacerbating and blunting forces of the broader sociocultural context. Unpacking the ST enables us to make several contributions. Specifically, we (1) demonstrate how marketplace stigma emerges and operates within sociocultural and historical milieus, (2) reveal the critical role that markets and market stakeholders can play in (de)stigmatization, (3) explore the implications of the ST for both marketing practice and public policy, and (4) offer a focused research agenda to further understanding of the linkages between marketplace stigma and stakeholder welfare.

\section{The Stigma Turbine}

Powerful sociocultural currents in the form of historical, institutional, and commercial "winds" energize the ST and form the sources of stigma. At the same time, countervailing winds shaped by the intentional actions by policy makers, marketers, the media, and other institutional players blunt the stigmatizing forces and create countercurrents of destigmatization as well. The three blades of the ST contain the potential targets for stigma: individuals, society, and the marketplace. Furthermore, we assert that four characteristics of the ST support our reliance on a framework rooted in the turbine metaphor and enable it to more fully capture the complex creation and countermanding of stigma within culture.

Table 1. Intersections of Stigma and the Marketplace: Recent Examples

Impact of Stigma

Positive Destigmatizing force:

- Kohl's partners with fashion designers to promote bargain shopping, diluting

"cheapskate" stereotype

- Target phases out gender-based signs in its children's bedding and toy aisles

Negative Stigmatizing force:

- United Airlines flight attendant denies Muslim passenger an unopened soda, explaining that the can could be used as a weapon, but sells an unopened beer to a non-Muslim passenger

- Indiana bakers refuse to make wedding cake for gay couple, citing conflict with religious beliefs

Marketplace Actor's Role

Positive coping support:

- Assisted-reproductive technologies help childless parents meet their goals of creating biologically related families

- Under Armour creates the "My Fitness Pal" app to help people count calories/ lose weight

Negative coping support:

- Drugs and alcohol may be used to deal with personal setbacks or mental health issues

- Credit cards may promote immoderate spending by people wishing to appear wealthier
Positive stereotypes:

- French wines have positive country-of-origin effects and are considered high quality

- Apple is considered cool and innovative

Negative stereotypes:

- Leading over-the-counter appetite suppressant Ayds suffers sales loss and is withdrawn from the market because of its phonetic similarity to AIDS

- Ballet schools have difficulty attracting boys because of parents' fear that dance will encourage homosexuality 
Figure 1. The Stigma Turbine

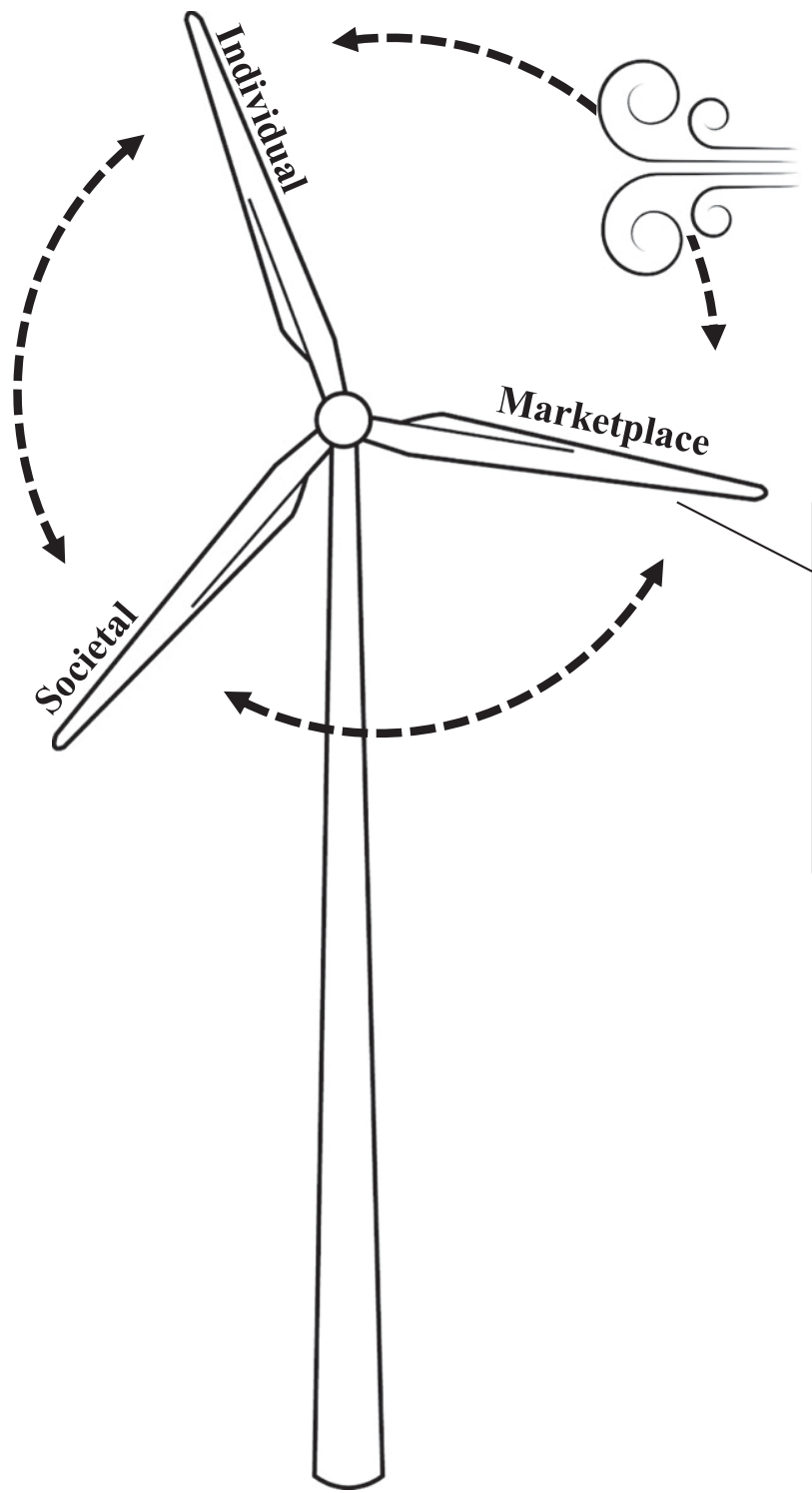

\section{Contextual Currents}

The historical, sociocultural, institutional (including public policy), and commercial winds that fuel the turbine.

The currents can increase or decrease stigma, changing the direction of rotation.

\section{The Blades}

The targets of (de)stigmatization.

Intervening factors can

- exacerbate stigma (responsibility, visibility, exclusion; power held by the stigmatizer).

- blunt stigma (social connectedness, proactivity, self-esteem; power held by the target).

\section{Unique Characteristics of the Stigma Turbine}

\section{Accommodating Intersectionality}

Stigmas are complex, overlapping, and multifaceted (Bos et al. 2013); however, most literature has examined stigma from an individual-identity perspective (e.g., Remedios and Snyder 2015). By contrast, the ST is explicitly intersectional (Gopaldas 2013) on three levels. First, each blade intersects with the sociohistorical environment from which stigmatized judgments arise. Sociopolitical events thus affect the orientation and magnification of stigmatized judgments. For instance, the stigmatization aimed at Arab and Muslim Americans has intensified since September 11 (Cainkar 2009; Khan 2014; Rodriguez Mosquera, Khan, and Selya 2013). Second, the three blades intersect with one another at the central hub of the ST, such that individuals, marketplaces, and societal institutions coproduce and codify values, beliefs, and motivations that affect the ways stigma is felt. Finally, multiple stigmas may interact within each blade. For example, some people's multiple stigmatized statuses arise from the coexistence of interdependent social-identity categories, such as race and gender (Crosby 2012; Saatçioğlu and Corus 2016).

\section{Capturing the Dynamic Nature of Stigma}

Rooted in and reflective of sociohistorical change (Shin, Dovidio, and Napier 2013), the rendering of stigma is an active, continually evolving process. Prior work has not fully examined how forceful change, along with increased mobility and interconnectivity at the individual, societal, and marketplace levels, influences stigma. Only a few marketing studies have touched on the dynamic nature of stigma (Adkins and Ozanne 2005; Saatçioğlu and Ozanne 2013). 


\section{Reflecting Bidirectional Tensions}

The ST rotates in both directions to fuel or quell stigmatization processes. Prior studies have focused on processes of stigma creation, coping, and intervention (Bos, Kok, and Dijker 2001). Some scholars have identified coping strategies that render stigmas less salient (Bos et al. 2013). These strategies include relabeling (Adkins and Ozanne 2005), normalizing (Nguyen, Chen, and Mukherjee 2014; Sandikçi and Ger 2010), mobilizing (Campbell and Deacon 2006; Scaraboto and Fischer 2013), and confronting various publics (Henry and Caldwell 2006). However, few studies have explored (1) how the forces that try to stigmatize or destigmatize exist in a dynamic interplay and (2) what factors help determine which side "wins" in such an exertion.

\section{Generating Power}

As contemporary discourses about obesity, same-sex marriage, and racial inequalities attest, prevailing sociocultural currents - or the winds that propel the ST in one direction or another-can generate abundant energy. The ST transforms energy from the sociocultural environment into a formidable (de)stigmatizing experience. Some studies have shown how individual stigmatizers and noncommercial social groups exploit, control, or exclude their targets (Link and Phelan 2001, 2014). However, the ST recognizes that marketplace actors also leverage their power to both increase and attenuate stigma as well as to shape well-being and future interactions.

\section{Contextual Currents Fueling the Stigma Turbine}

The ST captures how the sociocultural, historical, institutional, and commercial winds convert and shape felt (de)stigmatizing experiences. Ultimately, the stigma experienced within each blade of the turbine depends on how, when, and where such energy manifests. As we discuss subsequently, public policy actions can redirect these winds and reduce stigma.

\section{Sociocultural Winds}

Stigma depends on cultural institutions to provide, support, and enforce norms, behavioral cues, and social codes (Bos et al. 2013; Pescosolido et al. 2008). Governmental, religious, arts, educational, and medical institutions (re)produce symbols, mores, and folkways to inculcate and reinforce "normal" cultural behaviors. The ideologies these institutions communicate justify and legitimize sanctioned behaviors and identities. Furthermore, because culture makes certain aspects of identity salient, a stigma may be more relevant in one cultural context than in another, or not relevant at all. For example, Shin, Dovidio, and Napier (2013) find grouporiented cultures that stress conformity are more likely than individual-oriented ones to stigmatize people for "tribal" (e.g., racial) differences or perceived character flaws (e.g., drug addiction). Even cultures sharing common heritages may differ in their stigmatizing practices (e.g., "ginger" men in the United Kingdom typically are ridiculed for having red hair more than their American counterparts).

Within cultures, physical spaces can also shape stigma experiences. For example, lesbian, gay, bisexual, transgender, and questioning (LGBTQ) individuals living in rural areas experience stigmatization and discrimination more than their urban counterparts (Swank, Fahs, and Frost 2013). Retail spaces, public spaces, and neighborhoods may influence processes of felt stigma if these spaces bring aspects of people's identities into relief (Demangeot et al. 2013). Likewise, geographically imposed boundaries that reinforce regional or cultural differences, such as mountains or national borders, may influence the strength of stigmas.

Sociologically, communities serve as currents that (de)stigmatize by reinforcing shared understandings, norms, and prescriptions. Social groups that intend to offer succor may actually act as sources of stigma (e.g., some Israeli Fat Acceptance Movement members felt marginalized when gatekeepers deemed them not "fat enough"; Maor 2013). As potentially the most intimate social group, the family can serve as an especially painful source of stigma if members ridicule each other's traits, gender role expressions, or lifestyles.

\section{Historical Winds}

Stigmas exist in particular historical periods; thus, stereotypes associated with these attributions may diminish or increase over time. For instance, since the 1950s, stigmas associated with many forms of mental illness have decreased in the United States, yet people feared those diagnosed as mentally ill more during the 1990s than they did a halfcentury earlier (Phelan et al. 2000). Likewise, as family sizes have diminished in many developed nations, the stigma imposed on childless families has lessened (Van Gils and Kraaykamp 2008).

\section{Institutional Winds}

Governments as well as nongovernmental organizations (NGOs) may develop, operate, or perpetuate stigmas. Although their goal is to mitigate food insecurity among lowincome students, the implementation tactics of federally subsidized school lunch programs often contribute to stigmatizing outcomes (Pogash 2008). Participants are differentiated by space (a separate cafeteria line), food access (a separate, often limited menu), and checkout options (using identification cards, whereas nonrecipients use cash). Coupled with media representations of underprivileged families, these tactics may lead subsidized recipients to experience a heightened sense of stigma and demotivate eligible students from participating in the programs (Gundersen 2015).

Within the institutional winds, the forceful winds of public policy can exacerbate, tamp down, or even potentially reverse the direction of the ST. For example, the Supreme Court's endorsement of same-sex marriage could contribute to dampening the stigma of homosexuality. We revisit the potential public policy impact of institutional winds, as well as commercial winds (discussed next), in a subsequent section.

\section{Commercial Winds}

Through their product offerings, pricing policies, distribution practices, brand communication activities, and customer segmentation strategies, manufacturers, marketers, and the media can both perpetuate and attenuate stigma. For instance, advertisers sometimes stigmatize obesity with portrayals of overweight people as lazy, incompetent, and undisciplined 
(Pearl, Puhl, and Brownell 2012). While some stigmatizing depictions are unintentional, some brands promote stigmas to increase sales. Recently, the weight-loss firm Protein World displayed billboards with a bikini-clad model and the headline, "Are you beach body ready?" Despite widespread consumer complaints of fat-shaming and objectifying, the company pointedly attributed a sales spike to the campaign (Hinde 2015). Alternatively, corporate policies that fuel commercial winds sometimes help to destigmatize. Dove's groundbreaking "Real Beauty" campaign-featuring unretouched, nontraditional models-tackles stereotypes of female beauty. Similarly, Tylenol's \#HowWeFamily ad campaign helps normalize and destigmatize homosexuality by portraying LGBTQ couples grappling with typical middle-class experiences.

\section{The Blades of the ST}

\section{Individual Blade}

Stigma challenges the social identities of targeted people. Cognitive, affective, and behavioral processes, guided by the social or situational determinants of the stigma, shape their identities and coping responses (Yang et al. 2007). Some stigmatized people engage in stereotype embodiment, internalizing negative evaluations (Levy 2009). Onlookers may interpret the shame that self-stigmatizers project as evidence of social inferiority, calcifying the stigma (Yang et al. 2007). In contrast, other targets attribute negative evaluations to the stigmatizer's unwarranted prejudice. Still others engage in social comparisons within their stigmatized in-group, rather than with a privileged out-group (Crocker and Major 1989). Finally, some stigmatized people use marketplace resources to debunk stereotypes. However, this strategy can backfire. For example, low-income consumers might buy brands they think mask their poverty, only to find that the brands themselves trigger negative stereotypes (Hamilton 2012).

\section{Societal Blade}

Social groups, ranging from families and communities to entire subcultures, often find themselves to be targets of tribal stigma. For example, a family member's mental illness stimulates negative social attributions of the entire family (Corrigan and Miller 2004). In our contemporary consumer culture, the poor, the elderly, the obese, and other groups are vulnerable to systemic stigmatization (Commuri and Ekici 2008). Likewise, stigmas target subcultures whose values and ideologies run counter to what is considered normative in the broader culture. As an illustration, even though positive portrayals of nerds exist in the broader culture (e.g., the hit television show The Big Bang Theory), intellectually gifted adolescents still experience stigma and social exclusion for being different than the norm (Striley 2014).

\section{Marketplace Blade}

While marketplace actors may generate the commercial winds fueling stigma, those same actors-including brands, manufacturers, service providers, technologies, media, product categories, and consumers-may be targets of stigma (Kasperson, Jhaveri, and Kasperson 2001). Stereotypes related to country of origin (Peterson and Jolibert 1995) and product features (Ellen and Bone 2008) influence consumers' brand perceptions. Individuals, social groups, and cultures can stigmatize entire product categories (e.g., baby formula; Murphy 1999), product attributes (e.g., genetically modified foods; Ellen and Bone 2008) or product choices (e.g., socially inappropriate product assortments or brand names; Wooten 2006).

The marketplace also offers coping mechanisms to stigma targets, as evidenced when Star Trek fans who face ridicule for their shared passion can engage in "enclave withdrawal" at fan fests, reaping social support and a sense of community (Kozinets 2001). People also strategically leverage consumption practices to manage stigma: in Brazil, workingclass women use cleaning products to reframe their identity from "poor" to "poor and clean," reducing the stigmatization associated with their economic status (Neves 2004).

\section{Intervening Factors in the (De)Stigmatization Process}

Winds emanating from different sources (e.g., historical vs. sociocultural) or from different gusts within a single wind (e.g., liberal and conservative voices) may be mutually reinforcing and, thus, add multiplicative power to the ST. Alternatively, these winds may be in conflict and slow the turbine. In addition, psychological factors can influence the way the blades, as targets of stigma, absorb or deflect the winds. We classify each intervening factor in terms of its more typical influence (e.g., either contributing to or hindering stigma). However, we acknowledge that some factors could traverse either category, depending on whether the source or the target of the stigma controls them (e.g., by possessing power). Next, we summarize the factors we believe are most vital to developing policy and to fostering a research agenda around marketplace stigma. We acknowledge that, because of space constraints, the list is certainly not exhaustive.

\section{Factors Exacerbating Stigma}

Responsibility for stigma. Stigmatizers who perceive others as responsible for their stigmatizing conditions treat those targets more harshly than those perceived as victims of stigmatized outcomes (Jones et al. 1984). We theorize that this effect holds true for consumers, brands, and other entities within the marketplace blade as well. For example, stigmatized consumers may be blamed, which happened with a Centers for Disease Control social marketing campaign implying that women should refrain from drinking so they can fend off unwanted sexual advances. The campaign was interpreted as "one of the many victim-blaming pieces of advice ... women regularly hear about how they should avoid being raped" (Zielinski 2016). Similarly, during the big-box store expansion boom from 1998 to 2008, protestors blaming Wal-Mart for intentionally holding down wages and misusing natural resources blocked the discounter from opening $40 \%$ of proposed new stores (Yue, Rao, and Ingram 2013).

Visibility of the stigmatizing attribute. Visibility of a stigmatized attribute sharpens the felt stigma experience (Crocker and Major 1989; Jones et al. 1984). Because visibility and salience of stigma are often intertwined, they may 
represent a "damned if you do, damned if you don' t" outcome for the stigma target. On the one hand, onlookers' reactions may remind people with visible stigmatizing attributes of their stigma (Goffman 1963). On the other hand, people who can conceal the stigma may feel continual pressure to manage informational cues and their appearance. In addition, discursive winds may influence stigma salience. In a recent court settlement, the retail chain Hollister agreed to remodel all of its storefronts featuring porches and steps. Hollister's alternative entrances were frequently difficult to locate or locked, highlighting wheelchair-bound customers' disability (http:// creeclaw.org/hollister-settlement/).

Exclusion. The stigmatized are fundamentally concerned with not being accepted (Goffman 1963). Many stigma targets are constrained by a marketplace that ignores, minimalizes, or completely neglects their needs, wants, and desires (Baker 2006). The manufacturer Lululemon recently contributed to such marginalization with statements disparaging clothing for obese customers (Thomas and Peters 2015). Thus, cultural currents may fuel marketplace practices, and, in a vicious cycle, these practices may then reinforce cultural beliefs about a stigma (e.g., that the obese are unattractive and undeserving of stylish choices; Durso and Latner 2008).

Power held by the stigmatizer. Link and Phelan (2001, p. 375) assert, "Stigma is entirely dependent on social, economic and political power-it takes power to stigmatize." In a display of social and cultural power, Ruth (2008) finds even after South Africa lifted its apartheid laws, white customers often continued to disparage their black counterparts in stores, contributing to these consumers' discomfiture. This example reveals that groups stripped of formal power may retain the ability to stigmatize if mechanisms are not in place to restrict their ability to cast aspersions.

\section{Factors Blunting Stigma}

Power held by the stigmatized. Just as power in the hands of stigmatizers can exacerbate stigma, power in the hands of stigma targets can deflect negative attributions. For example, as elite Turkish women have gained more social power in society, they have exerted greater influence on the evolution of the practice of veiling. Indeed, veiling has become a way for elite women to express their sense of fashion. Moreover, Turkey's cultural influence on the surrounding geographical regions has helped shaped veiling practices in neighboring countries (Sandikçi and Ger 2010).

Social connectedness. Crocker and Major's (1989) analyses of the challenges facing those who conceal their stigmatized identities suggest that connectedness to in-group members affects experiences of stigma. Members of stigmatized groups protect their self-concepts by attributing negative experiences to prejudice against their group, comparing their outcomes with those of the in-group, rather than with a privileged out-group, or selectively devaluing attributes on which their group fares poorly and valuing those on which they excel. In a study of stigmatized trailer park residents, Saatçioğlu and Ozanne (2013) show how residents negotiate social status by comparing themselves favorably with their neighbors who engage in criminal behaviors. Yet those with weaker ties to other group members possess less information about their group's relative performance, limiting their ability to bolster their self-esteem by relying on in-group comparison or out-group devaluing strategies (Crocker and Major 1989).

Proactivity. Consumer normalcy involves a desire to live like and be accepted by other consumers as well as be acceptable to oneself in consumption contexts (Baker 2006). Investigating blind people's shopping experiences, Baker (2006) demonstrates how this group proactively signals their consumer normalcy in the marketplace by leveraging four strategies to (de)stigmatize their blindness while shoppingparticipating, achieving distinction, demonstrating competence and control, and being perceived as equals. In so doing, these shoppers reclaim their agency, which serves to deflect attention away from their disability.

Self-esteem. Research on consumer vulnerability parallels and echoes research on stigma, because many stigmatized groups become more vulnerable as a result of stigmatization. Factors that increase the likelihood of vulnerability include individual characteristics, individual states, and external conditions beyond the person's control (Baker, Gentry, and Rittenburg 2005). Wooten (2006) finds that teenagers are particularly vulnerable as objects of ridicule when seen to display "stigma symbols" (Goffman 1963), or objects that draw attention to undesirable aspects of their identity and contribute to debasement (e.g., high-water pants).

\section{Summary}

The ST conceptualizes stigma as conveyed through currents emanating from sociocultural, historical, institutional, and commercial winds. These sources then propel the individual, societal, and marketplace blades in the same or competing directions. Depending on the strength and accessibility of various intervening factors, the targets of stigma contained within these blades may be more or less successful in combating the negative outcomes pertaining to stigma-and may become advocates for destigmatization as well. In the next section, we explore how stakeholders can work toward achieving these more positive outcomes.

\section{Public and Marketing Policy Implications}

Blowing in one direction, the institutional and commercial winds propel the creation and perpetuation of stigma experienced by the targets contained in the blades of the ST. Yet intentional actions by policy makers and NGOs in the institutional wind and by marketers and other stakeholders enmeshed in the commercial wind can tamp down-or potentially reverse - the direction of the ST. For example, gusts from the Supreme Court's endorsement of same-sex marriage, Disney Gay Days, and Ellen DeGeneres's celebrity status all dampened the stigma of homosexuality. Next, we discuss how practices and policies can help dismantle and defuse the systemic forces that create stigmatization.

While stigma can be experienced at the individual and societal levels, we focus our policy discussion on stigma in the marketplace, our specific area of interest in this article. We begin by introducing a new tool, the Stigma Audit, to help marketers, policy makers and other institutional stakeholders examine the implications of their marketplace offerings, and identify both subtle and explicit stigmatizing activities. We then provide specific policy prescriptions for neutralizing stigma. 


\section{The Stigma Audit}

The stigmatizing effects of activities by marketers and policy makers are often unintended, unanticipated, and overlooked. We propose stakeholders complete a Stigma Audit to systematically assess the (de)stigmatizing influences of extant or planned policies and marketing activities. As we outline in Table 2, the Stigma Audit begins by identifying stakeholders who are potentially affected by the proposed activity, with particular attention paid to stigmatized populations. We advocate for broadly defining stakeholders (e.g., internal and external, direct and indirect). Next, the audit calls for an assessment of the messages and meanings of each activity. Capturing the contextual nature of stigma, it considers meaning variations across cultures, populations, and communities. The audit concludes with an outcomes assessment for both stakeholders and the organization. Qualitative techniques such as focus groups and depth interviews may help stakeholders better understand and respond to subtle stigmatizing activity uncovered in the audit.

\section{Marketer and Policy Actions to Counter Stigmatization}

The ST's contextual currents create and carry the cultural codes and structures that promote stigma. Those structures relate to what Link and Phelan (2001) describe as the four steps of stigma formation: (1) labeling human differences; (2) forming stereotypes by connecting labels to negative attributions; (3) mentally separating the labeled from the mainstream; and (4) by enacting the previous three steps, justifying discrimination, which leads to status loss and outcome inequity. In this subsection, we deconstruct those four steps to identify specific, theory-driven policy recommendations for marketers and policy makers seeking to destigmatize within the marketplace context. Table 3 summarizes the policy prescriptions. In addition, because all policies are inherently bounded by resource constraints such as cost, time, and human effort/labor, the table discusses the limitations to policy as well as the benefits.

\section{Step 1: Evaluate Practices of Labeling Human Differences}

All human differences can potentially be labeled, but some labels are more socioculturally and historically salient than others. For instance, birth month and eye color are less problematic than race, gender, and physical condition (Link and Phelan 2001). Once a label takes hold, however, it may become understood within a culture as an indelible distinction. Marketers can avoid stigmatizing labels by choosing value-neutral product and promotional titles. For example, fashion retailer Lane Bryant has replaced the "plus-size" moniker with "her size," and The Association for Retarded Citizens has rebranded itself as "The Arc." Over time, however, once-innocuous terms applied to stigmatized concepts may acquire undesirable connotations (Pinker 2003). Marketers must remain prepared to periodically update terminology with respect to product names, packaging, names of promotional activities, and so on.

\section{Step 2: Defuse Stereotypes: Break the Connections Between Labels and Negative Attributes}

Stereotypes emerge when people's cultural beliefs and personal experiences lead them to forge a mental connection between labeled groups and undesirable characteristics. Government officials and news editors may inadvertently aggravate stigmatizing stereotypes pertaining to mental

Table 2. The Stigma Audit for Policies and Programs

Audit Questions

Stakeholders

Content

Outcome
- Whom could the activity potentially help/harm, directly and indirectly?

- How are the stakeholders a stigmatized population/community? Does the activity involve a partner organization that may enhance or reduce stigma?

- How have stakeholders reacted to similar activities that led to (de)stigmatizing effects?

- What potentially stigmatized attributes will the activity highlight?

- How is the activity intended to reduce stigma?

- Does the activity draw on or enhance negative stereotypes through visual imagery and/or discourse? If yes, how? And how can visual imagery be adjusted to reduce such negative stereotyping?

- Have differing cultural interpretations that could potentially stigmatize readers/viewers (within and outside the target audience) been considered and addressed?

- Have ambiguous meanings been identified and addressed?

- Have unintended consequences been considered?

- Does the outcome of the activity hold the potential for (de)stigmatization?

- How will the organization monitor the actual (de)stigmatizing impact of the activity?

- Does the potential for destigmatization outweigh the potential for stigmatization?

- Whose power is enhanced/harmed by the activity?

- How could the activity affect the vulnerability of stakeholders?

- What impact might the activity have on the broader sociocultural discourses that pertain to the (de)stigmatized attributes?

- What are the potential consequences of the activity on the identity, reputation, and effectiveness of the stakeholders?

- What are the potential consequences on the identity, reputation, and effectiveness of the sponsoring institution/corporation? 


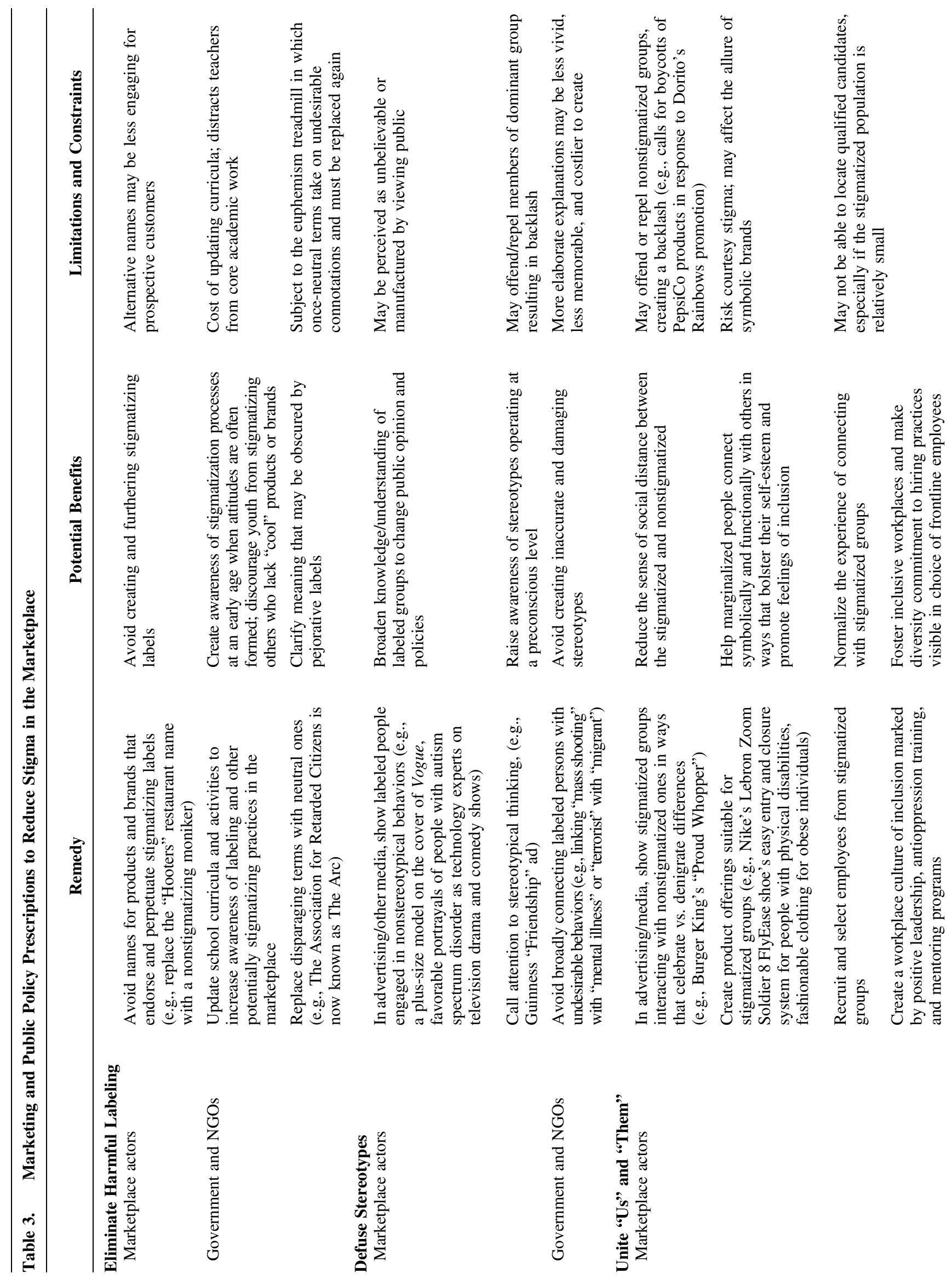




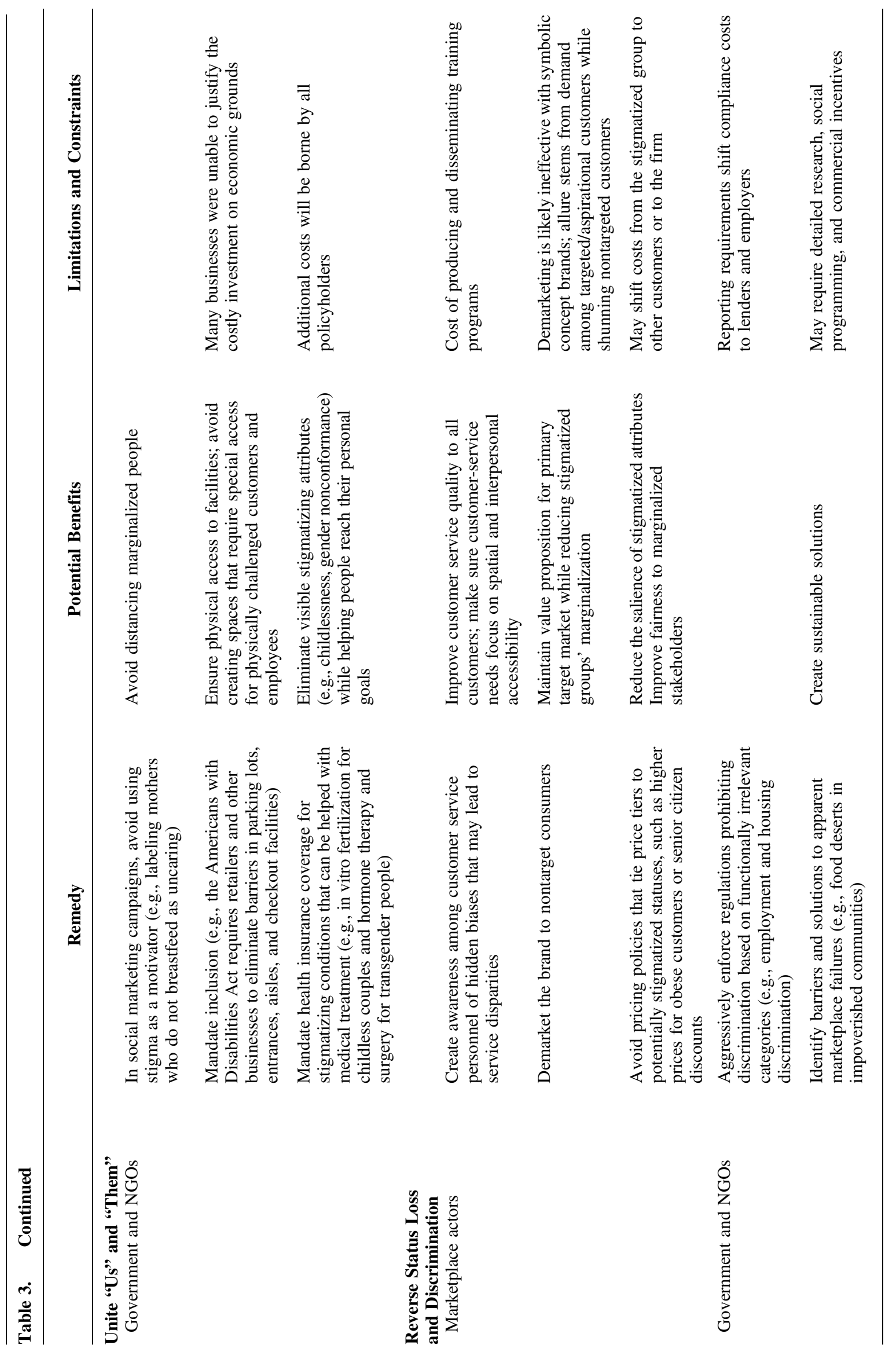


health when, for example, mass shooting is linked with mental illness within the discourse of gun sales (McGinty, Webster, and Barry 2013). Stereotypes are difficult to disrupt because contradictory evidence is often uncertain, ambiguous, and easily dismissed (Tajfel 1981). Thus, marketers should strive to communicate counterfactual information vividly. Within the realm of consumer culture, Lady Gaga's song "Born this Way" disrupted the stereotype ascribing deviant choices to LGBTQ persons. Likewise, Guinness challenged the disability stereotype with its "Friendship" ad showing six men playing an intense game of wheelchair basketball. Near the end of the spot, five of the men rise from their wheelchairs, implying that they used the chairs to include their wheelchair-using friend. The ad reinforced the message that disability-related differences are superficial when compared with the authenticity of their human connections.

\section{Step 3: Unite, Rather Than Segregate, "Us" and "Them"}

Negative stereotypes portray the stigmatized out-group as homogeneous and different, thus justifying the in-group's quest for mental distance (Tajfel 1981). Marketers can interrupt the separation process by calling attention to the similarities between people in the two groups. During San Francisco's Pride Celebration, Burger King sold a "Proud Whopper" that differed from the traditional version only in its rainbow-colored wrapper. A note on the packaging, "We are all the same inside," underscored the message (Steinmetz 2014).

Retailers and service providers can build bridges between their customers and stigmatized groups. Stores that recruit employees from stigmatized groups create opportunities for shoppers to discover commonalities through normal retail interactions. However, simply hiring stigmatized employees is not sufficient, because stigmatizers may also marginalize the coworkers of these employees, and perhaps even the retailer (Kulik, Bainbridge, and Cregan 2008). Instead, firms must create a retail culture of acceptance through ongoing antioppression training, mentoring, ally programs, advertising communications, and vigilance against ostracism. Retail signage can also serve as a bridge to stigmatized groups. For example, all-gender signage on restroom facilities signals connections with transgender people. Firms can also demonstrate a culture of inclusion by endorsing key employees who publicly address stigmatizing as, for example, Apple's Tim Cook and Facebook's Sheryl Sandberg have done.

The need to focus on uniting, rather than separating, extends to NGOs using social marketing campaigns to bring about behavioral change. For example, healthism-motivated campaigns to increase breastfeeding, weight management, and tobacco avoidance have stigmatized nonparticipants as uncaring, unattractive, and undisciplined (Gurrieri, Previte, and Brace-Govan 2013). Efforts to improve social welfare do not justify marginalizing people (Brenkert 2002).

\section{Step 4: Reverse Status Loss and Discrimination}

Policies to reverse discrimination are more effective when they take into consideration the stigmatizer's intent (Hirsh 2014). Government regulation is particularly effective for discrimination arising from the intentional disparate treatment of marginalized groups. In the United States, civil rights laws mandate retailers to serve customers regardless of race; the Equal Pay Act bars sex-based wage discrimination; and the Fair Housing Act prohibits discrimination in the arena of real estate transactions based on race, religion, and family size. Aggressive enforcement is often required to assure the protections, and additional legislation is needed to protect LGBTQ people and others.

Discrimination is more likely to arise, however, from policies and practices that seem neutral but, in use, have a disparate negative impact on stigmatized groups (Hirsh 2014). For example, sales districts assigned on the basis of perceived cultural and social fit between the sales representative and the client may relegate minority employees to less profitable customer segments (Jones et al. 1998). Likewise, retailers who reserve preferred parking places for eco-friendly cars may marginalize poorer people who cannot afford these typically more expensive vehicles. Similarly, the reluctance of modern supermarkets to establish locations in impoverished neighborhoods may improve profits, but it also impedes local residents' access to affordable, healthful foods. Policy solutions in this realm are complex. To begin with, because firms can justify their actions as pertinent to profit and expansion goals, government prosecution under existing discrimination laws is ineffective (Hirsh 2014). Instead, spotlighting the discriminatory impact may prompt managerial change if the discrimination is unintentional. For example, the federal government plans to require large employers to report pay by race, gender, and ethnicity, with the idea that the visibility of pay disparities will prompt voluntary actions (Paquette and Harwell 2016). Other solutions may require the collaboration of business, government, and community groups. In the case of "food deserts" (locations in underprivileged areas devoid of fresh food retailers), new research has shown that the introduction of new stores promotes little change in entrenched eating habits (Dubowitz et al. 2015). Instead, social marketing programs to prompt new food purchasing behaviors must also be implemented.

Still more difficult to unravel is discrimination arising not from corporate policy but from the interplay of cognitive biases and service provider discretion. Health care service providers often hold an implicit bias against obese patients, viewing those patients as culpable for their health problems, noncompliant, and unmotivated (Puhl and Heuer 2009). Strategies involving education (Crandall 1994) and greater social consensus regarding positive views of stigmatized people (Zitek and Hebl 2007) have proven effective in combating such biases and could be employed across a variety of corporate and institutional contexts.

\section{Policy Challenges Arising from Marketplace Failures}

Thoughtful marketers and policy makers can improve consumer welfare by conducting a Stigma Audit and by paying attention to labeling, stereotyping, and separating behaviors that promote discrimination. Although many of the aforementioned destigmatizing actions can be implemented relatively inexpensively, other initiatives could erode brand equity. In those cases, while some marketers might choose to pursue destigmatization as a moral imperative, many others will stall until incentives are aligned or until legislation mandates change. Next, we identify four such areas that defy 
simple policy solutions and are worthy of additional thought and research.

\section{The Dark Side of Market Segmentation}

Customer-centric marketers identify prospective customer segments, select those to pursue, and design winning value propositions to satisfy their target markets' needs and preferences. The process implies that firms will market differently to different segments and some consumers' needs will be fulfilled while others' will be ignored, potentially propagating and even propelling stigmas. For example, consumers cherish luxury brands in part because only a few can afford them, stigmatizing poorer or less-connected consumers. However, selectively demarketing a brand to nontargeted consumers is unlikely to appeal to symbolic brands whose allure depends on building demand among both targeted and aspirational customers while keeping the brand inaccessible to nontargeted customers (Park, Jaworski, and Maclnnis 1986). How can marketers be exclusive without being exclusionary?

\section{The Hazard of Equitable Treatment}

Paradoxically, other stigmatizing marketing practices may be motivated by the pursuit of procedural justice for all customers. For example, obese customers pay higher disability and life insurance premiums, reflecting their greater actuarial risk. Reducing these customers' premiums would either increase the premiums charged to the entire risk pool or diminish firm profits. Similarly, some airlines require obese passengers to purchase two seats if one is too small. Accommodating the obese passenger at no additional charge means forgoing profit from a seat that could be sold to another passenger or raising prices on all other seats to maintain revenue targets. Should stigmatized people bear these incremental costs? Arguably, a higher price might be morally justifiable if the stigmatized attribute-here, obesity-is under the person's control. In practice, controllability is difficult to assess; obesity and other highly stigmatized conditions are rooted in a web of environmental, biological, and behavioral factors (Corrigan, Markowitz, and Watson 2004). How can marketers price fairly when serving stigmatized groups requires resource-intensive effort?

\section{Creating Products That Profit from Stigma}

Many marketplace offerings profit from exploiting stigmatized identities. Consider how Halloween haunted asylums and straightjacket costumes portray mental health patients as dangerous freaks. Ethical theories rooted in deontic (adherence to duty) and virtue (moral character) principles counsel firms to avoid such products. The ethicality of products that provide coping mechanisms for stigmatized consumers is more complex. For instance, promoting weightloss products may perpetuate the obesity stigma (Scaraboto and Fischer 2013). How can brands help people cope with a stigma without perpetuating the stigma?

\section{Balancing Individual Dignity with Social Welfare}

Policy prescriptions designed to provide needed solutions may inadvertently legitimize stigmatization. As noted previously, the subsidized meal programs for low-income students can easily contribute to their labeling as "poor."
Similarly, purchasing clothing at thrift stores can connote poverty. How can offerings be designed and provided to preserve individual dignity and avoid unintended labeling and separation that may result in stigma creation?

\section{Summary}

As these dilemmas illustrate, marketing and policy prescriptions for destigmatization may strain firms, other consumers, or the public at large. In some cases, research may offer a path to incentive alignment. For example, Ruth and Simonin (2003) find that brands sponsoring controversial events can insulate themselves from consumer backlash by recruiting other brands. Apparently, the presence of multiple sponsors inhibits the formation of a courtesy stigma as the larger number of brands exerts a normalizing effect on the sponsorship. In other cases, elegant solutions may not emerge. Instead, eliminating stigma may require a "hard form" of stakeholder theory in which firms sacrifice profits to mitigate stigma-creating outcomes (Laczniak and Murphy 2012) and commit to human flourishing as the paramount business goal (Hill and Martin 2014).

\section{A Fresh Lens for Investigating Stigma: Research Implications}

The ST provides an integrative view of the stigma experience within and across cultures. To our knowledge, it is the first model to capture both the stigmatization and the destigmatization processes, to depict stigmatization as an ongoing, nonlinear process with ebbs and flows shaped by the sociohistorical environment, and to describe in detail the role of the marketplace as both a contextual wind and a structural locus where (de)stigmatization occurs. As such, the model offers a novel vantage point to identify underresearched areas related to stigma. Organized by the various components of the ST, potential avenues for inquiry to broaden the field's understanding of marketplace stigma appear in Table 4.

\section{Deepening Understanding of the Contextual Currents}

Because historical, social, and cultural currents shape the felt stigma experience, symbols can evolve into or devolve from stigmatized entities (Sandikçi and Ger 2010). Researchers might explore the processes by which stigmas and their associated symbols evolve across historical periods, how stigmatized cultural practices and consumption rituals involving constellations of products and brands undergo perceptual shifts, and how the actions of marketplace stakeholders influence such changes. Consider that tattoos, the original "stigmata" applied to slaves or criminals, which were long considered marks of shame, have become "voluntary stigma" (Sanders 1988, p. 397) embraced by consumers to assert their uniqueness and demonstrate control over their bodies. Similarly, once firmly entrenched in the (itself historically stigmatized) American South, NASCAR expanded nationwide and underwent an image transformation among both consumers and mainstream advertisers, which now flock to sponsor races and drivers (Howell 1997). Understanding the macro forces that give rise to such evolutions and transformations in symbol meanings could be a fruitful 
Table 4. Research Avenues Inspired by the Stigma Turbine

\section{Research Questions}

Contextual currents

The blades

Intervening factors

The central hub/intersection
- How do physical spaces and geographic boundaries shape stigma experiences?

- How do increased mobility and interconnectivity at the individual, societal, and marketplace levels influence stigma?

- How do stigmas and their associated symbols evolve across historical periods or differ across sociocultural contexts?

- How do objects become status symbols in one cultural context and stigma symbols in another?

- How do media institutions contribute to the creation, perpetuation, evolution and/or attenuation of stigmas?

- How do people acquire and exercise the power to stigmatize the products and practices of commercial institutions?

- What factors contribute to stigmatization within stigmatized groups?

- How does a market offering become identified as part of the consumption constellation of a stigmatized group?

- How can market segmentation contribute to feelings of stigmatization?

- How does the intersectionality of stigmatized attributes shape personal identity? How do consumers cope with this type of stigma?

- How does the nature and availability of information affect people's power to perpetuate, attenuate, or manage stigma?

- What strategies can market actors use to reframe stigmas?

- Which intervening factors contribute to the stigmatization of positive deviance?

- How have technology and social media affected the balance of power between stigmatizers and the stigmatized?

- What factors, other than those identified in the article, contribute to or hinder stigma?

- How do individuals and society perceive commercial efforts to profit from creating, perpetuating, or alleviating stigma?

- How can marketers be exclusive without being exclusionary?

- How can marketers price fairly when serving stigmatized groups is resource-intensive?

- How can brands help people cope with a stigma without perpetuating the stigma?

- How can offerings for marginalized people be designed and provided in a way that avoids unintended labeling and separation that may result in deeper stigma?

- Social marketing: How can stigma be used to improve social welfare without affecting the rights and dignity of individuals?

- How do antistigma laws influence attitudes toward vulnerable groups (e.g., how does the U.S. Supreme Court decision to legalize gay marriage influence the perception of responsibility for homosexuality)?

- When do brand alliances with stigmatized groups reduce stigma, and when do such alliances tarnish brand image? research path, helping marketplace stakeholders contribute to the (de)stigmatizing of symbol-laden practices.

\section{Experiencing Stigma: The Blades}

A crucial need exists to understand how stigmatization of intersecting social categories affects people's sense of wellbeing, and how to guide destigmatization initiatives. Researchers might explore how people who forge new identity paths, but who pay a stigma-laden price in doing so, leverage resources from their social groups, the marketplace, and the broader culture. For example, stay-at-home dads in North America face stigma not only because they engage in parenting behavior still typically coded as feminine but also because they forgo a breadwinner role deeply rooted in normative masculinity (Coskuner-Balli and Thompson 2013). To combat stigma emanating from these multiple fronts, stay-athome dads deliberately leverage the marketplace by engaging in entrepreneurial (masculine) behavior to serve the needs of, and legitimize, their subculture. Research examining the ramifications of commercial or other institutions choosing to restrict or discriminate when interacting with people whose social classifications contribute to multiple, exacerbated stigmas would, likewise, contribute to increased understanding.

\section{Exacerbating and Blunting Intervening Factors}

Salient questions that pertain to the intervening factors we identify include: How and why do the factors exacerbating or blunting stigma shape stigmatizers' and targets' behaviors? What implications for destigmatization initiatives arise? Further research could identify, explore, and evaluate other intervening factors. For instance, how does the role and propagation of social media by various marketplace stakeholders influence efforts to (de)stigmatize objects or others?

\section{Intersection of the Individual, Marketplace, and Societal Blades}

The intersection illustrates the importance of incorporating a focus on marketplace stigmatization into the interdisciplinary canon of research on stigma. Consider, for example, research 
related to gender-preference and gender-identity stigma. Cross-cultural policy research might examine how the spatial "wind" that describes homosexuality as a controllable choice continues to perpetuate stigmatization in certain countries, cultures, and communities. How has the Supreme Court's groundbreaking decision to legalize same-sex marriage influenced the perception of responsibility for homosexuality? What factors influence the ability of businesses to be more open and inclusive of LGBTQ consumers-or more exclusive? What are the consequences for those decisions for both consumers and businesses? More generally, to what extent do marketing efforts perpetuate stigmas they aim to alleviate? How do individuals and society respond to commercial efforts to profit from such actions? Under what conditions do these efforts shift from being acceptable (e.g., weight-loss products) to being controversial (e.g., skinlightening products)? Such questions should bolster the salience of stigma as a research topic.

\section{Conclusion}

The ST is a novel, holistic, and systematic framework for studying stigma formation and resistance. In particular, the ST provides a clear metaphoric representation of key forces within and across cultures that can foster (de)stigmatization: sociocultural currents in the form of historical, institutional, and commercial winds; individual, society, marketplace blades containing the potential targets for stigma; and dimensions within these blades that can exacerbate or blunt stigma. The ST also prominently identifies the marketplace as a source and a target for stigma, assuring that future discourse on commercial and cultural institutions as forces of marginalization or inclusiveness incorporates stigma as a focal topic.

The Stigma Audit offers an evaluative tool for stakeholders assessing the potential consequences of their actions. Furthermore, the ST shapes a rich understanding of the marketing and public policy related to marketplace stigma and guides a research agenda to advance our understanding of how consumers, marketers, social and governmental institutions, and other stakeholders confront the challenges of managing threatened identities. Much work remains, and we believe the ST offers a compelling framework for academics and practitioners pursuing this area of inquiry. The time is ripe to shape a deeper and broader understanding and resolution of stigma at the intersection of the cultural, social, and commercial spheres.

\section{References}

Adkins, Natalie Ross and Julie L. Ozanne (2005), "The Low Literate Consumer," Journal of Consumer Research, 32 (1), 93-105.

Arnould, Eric J. and Craig J. Thompson (2005), "Consumer Culture Theory (CCT): Twenty Years of Research," Journal of Consumer Research, 31 (4), 868-82.

Baker, Stacey Menzel (2006), "Consumer Normalcy: Understanding the Value of Shopping through Narratives of Consumers with Visual Impairments," Journal of Retailing, 82 (1), 37-50.

James W. Gentry, and Terri L. Rittenburg (2005), "Building Understanding of the Domain of Consumer Vulnerability," Journal of Macromarketing, 25 (2), 128-39.
Bos, Arjan E.R., Gerjo Kok, and Anton J. Dijker (2001), "Public Reactions to People with HIV/AIDS in the Netherlands," AIDS Education and Prevention, 13 (3), 219-28.

Bos, Arjan E. R., John B. Pryor, Glenn D. Reeder, and Sarah E. Stutterheim (2013), "Stigma: Advances in Theory and Research," Basic and Applied Social Psychology, 35 (1), 1-9.

Brenkert, George G. (2002), "Ethical Challenges of Social Marketing," Journal of Public Policy \& Marketing, 21 (Spring), $14-25$.

Cainkar, Louise A. (2009), Homeland Insecurity: The Arab American and Muslim American Experience after 9/11. New York: Russell Sage Foundation.

Campbell, Cathy and Harriet Deacon (2006), "Unravelling the Contexts of Stigma: From Internalisation to Resistance to Change," Journal of Community \& Applied Social Psychology, 16 (6), 411-17.

Campbell, Margaret C. and Gina S. Mohr (2011), "Seeing Is Eating: How and When Activation of a Negative Stereotype Increases Stereotype-Conducive Behavior," Journal of Consumer Research, 38 (3), 431-44.

Commuri, Suraj and Ahmet Ekici (2008), "An Enlargement of the Notion of Consumer Vulnerability," Journal of Macromarketing, 28 (2), 183-86.

Corrigan, Patrick W., Fred E. Markowitz, and Amy C. Watson (2004), "Structural Levels of Mental Illness Stigma and Discrimination," Schizophrenia Bulletin, 30 (3), 481-91.

_ and Frederick E. Miller (2004), "Shame, Blame, and Contamination: A Review of the Impact of Mental Illness Stigma on Family Members," Journal of Mental Health, 13 (6), 537-48.

Coskuner-Balli, Gokcen and Craig J. Thompson (2013), "The Status Costs of Subordinate Cultural Capital: At-Home Fathers' Collective Pursuit of Cultural Legitimacy Through Capitalizing Consumption Practices," Journal of Consumer Research, 40 (1), $19-41$.

Crandall, Christian S. (1994), "Prejudice Against Fat People: Ideology and Self-Interest," Journal of Personality and Social Psychology, 66 (5), 882-94.

Crocker, Jennifer and Brenda Major (1989), "Social Stigma and Self-Esteem: The Self-Protective Properties of Stigma," Psychological Review, 96 (4), 608-30.

Crockett, David, Sonya A. Grier, and Jacqueline A. Williams (2003), "Coping with Marketplace Discrimination: An Exploration of the Experiences of Black Men," American Marketing Science Review, 2003 (4), 1-21.

Crosby, Elizabeth (2012), "Exploring Stigma, Identity Gaps, and Consumption," dissertation, University of Illinois at UrbanaChampaign, (accessed March 17, 2016), [available at https:// www.ideals.illinois.edu/bitstream/handle/2142/30940/Crosby_ Elizabeth.pdf?sequence $=1]$.

Demangeot, Catherine, Natalie Ross Adkins, Rene Dentiste Mueller, Geraldine Rosa Henderson, Nakeisha S. Ferguson, James M. Mandiberg, et al. (2013), "Toward Intercultural Competency in Multicultural Marketplaces," Journal of Public Policy \& Marketing, 32 (Special Issue), 156-64.

Dovidio, John F., Brenda Major, and Jennifer Crocker (2000), "Stigma: Introduction and Overview," in The Social Psychology of Stigma, T.F. Heatherton, R.E. Kleck, M.R. Hebl, and J.G. Hull, eds. New York: Guilford Press, 1-28.

Dubowitz, Tamara, Madhumita Ghosh-Dastidar, Deborah A. Cohen, Robin Beckman, Elizabeth D. Steiner, Gerald P. Hunter, et al. (2015), 
"Diet and Perceptions Change with Supermarket Introduction in a Food Desert, but Not Because of Supermarket Use," Health Affairs, 34 (11), 1858-68.

Durso, Laura E. and Janet D. Latner (2008), "Understanding SelfDirected Stigma: Development of the Weight Bias Internalization Scale," Obesity, 16 (S2), S80-86.

Ellen, Pam Scholder and Paula Fitzgerald Bone (2008), "Stained by the Label? Stigma and the Case of Genetically Modified Foods," Journal of Public Policy \& Marketing, 27 (Spring), 69-82.

Goffman, Erving (1963), Stigma: Notes on the Management of Spoiled Identity. New York: Simon \& Schuster.

Gopaldas, Ahir (2013), "Intersectionality 101," Journal of Public Policy \& Marketing, 32 (Special Issue), 90-94.

Gundersen, Craig (2015), "Food Assistance Programs and Child Health," Future of Children, 25 (1), 91-109.

Gurrieri, Lauren, Josephine Previte, and Jan Brace-Govan (2013), "Women's Bodies as Sites of Control: Inadvertent Stigma and Exclusion in Social Marketing," Journal of Macromarketing, 33 (2), 128-43.

Hamilton, Kathy (2012), "Low-Income Families and Coping Through Brands: Inclusion or Stigma?" Sociology, 46 (1), 74-90.

Henry, Paul Conrad and Marylouise Caldwell (2006), "SelfEmpowerment and Consumption: Consumer Remedies for Prolonged Stigmatization," European Journal of Marketing, 40 (9/10), 1031-48.

Hill, Ronald Paul and Kelly D. Martin (2014), "Broadening the Paradigm of Marketing as Exchange: A Public Policy and Marketing Perspective," Journal of Public Policy \& Marketing, 33 (Spring), 17-33.

Hinde, Natasha (2015), "Plus-Size Model Ashley Graham Delivers Perfect Response to Protein World's 'Beach Body' Advert," Huffington Post, (accessed June 7, 2016), [available at http:// www.huffingtonpost.co.uk/2015/04/30/swimsuitsforall-reactsprotein-world-advert-ashley-graham_n_7181292.html].

Hirsh, C. Elizabeth (2014), "Beyond Treatment and Impact: A Context-Oriented Approach to Employment Discrimination," American Behavioral Scientist, 58 (2), 256-73.

Ho, Mary and Stephanie O’Donohoe (2014), "Volunteer Stereotypes, Stigma, and Relational Identity Projects," European Journal of Marketing, 48 (5/6), 854-77.

Howell, Mark D. (1997), From Moonshine to Madison Avenue: A Cultural History of the NASCAR Winston Cup Series. Bowling Green, $\mathrm{OH}$ : Popular Press.

Jones, Edward E., Amerigo Farina, Albert H. Hastorf, Hazel Markus, Dale T. Miller, and Robert A. Scott (1984), The Dimensions of Stigma: The Psychology of Marked Relationships. New York: W.H. Freeman Company.

Jones, Eli, Jesse N. Moore, Andrea J.S. Stanaland, and Rosalind A.J. Wyatt (1998), "Salesperson Race and Gender and the Access and Legitimacy Paradigm: Does Difference Make a Difference?" Journal of Personal Selling \& Sales Management, 18 (4), 71-88.

Kasperson, Roger E., Nayna Jhaveri, and Jeanne X. Kasperson (2001), "Stigma and the Social Amplification of Risk: Toward a Framework of Analysis," in Risk, Media and Stigma: Understanding Public Challenges to Modern Science and Technology, J. Flynn, P. Slovic, and H. Kunreuther, eds. London: Earthscan, 9-27.

Keene, Danya E., Sarah K. Cowan, and Amy Castro Baker (2015), "'When You're in a Crisis Like That, You Don't Want People to
Know': Mortgage Strain, Stigma, and Mental Health," American Journal of Public Health, 105 (5), 1008-12.

Khan, Saera R. (2014), "Post 9/11: The Impact of Stigma for Muslim Americans," Peace and Conflict, 20 (4), 580-82.

Kozinets, Robert V. (2001), "Utopian Enterprise: Articulating the Meanings of Star Trek's Culture of Consumption," Journal of Consumer Research, 28 (1), 67-88.

Kulik, Carol T., Hugh T.J. Bainbridge, and Christina Cregan (2008), "Known by the Company We Keep: Stigma-by-Association Effects in the Workplace," Academy of Management Review, 33 (1), 216-30.

Laczniak, Gene R. and Patrick E. Murphy (2012), "Stakeholder Theory and Marketing: Moving from a Firm-Centric to a Societal Perspective," Journal of Public Policy \& Marketing, 31 (Fall), 284-92.

Levy, Becca (2009), "Stereotype Embodiment a Psychosocial Approach to Aging," Current Directions in Psychological Science, 18 (6), 332-36.

Link, Bruce G. and Jo C. Phelan (2001), "Conceptualizing Stigma," Annual Review of Sociology, 27, 363-85.

Link, Bruce G. and Jo Phelan (2014), "Stigma Power," Social Science \& Medicine, 103 (February), 24-32.

Maor, Maya (2013), “'Do I Still Belong Here?' The Body's Boundary Work in the Israeli Fat Acceptance Movement," Social Movement Studies, 12 (3), 280-97.

Matta, Shashi and Valerie S. Folkes (2005), "Inferences About the Brand from Counterstereotypical Service Providers," Journal of Consumer Research, 32 (2), 196-206.

McGinty, Emma E., Daniel W. Webster, and Colleen L. Barry (2013), "Effects of News Media Messages About Mass Shootings on Attitudes Toward Persons with Serious Mental Illness and Public Support for Gun Control Policies," American Journal of Psychiatry, 170 (5), 494-501.

Murphy, Elizabeth (1999), “'Breast Is Best': Infant Feeding Decisions and Maternal Deviance," Sociology of Health \& Illness, 21 (2), 187-208.

Neves, Livia Martins Pinheiro (2004), "Cleanness, Pollution and Disgust in Modern Industrial Societies: The Brazilian Case," Journal of Consumer Culture, 4 (3), 385-405.

Nguyen, Hieu P., Steven Chen, and Sayantani Mukherjee (2014), "Reverse Stigma in the Freegan Community," Journal of Business Research, 67 (9), 1877-84.

Paquette, Danielle and Drew Harwell (2016), "Obama Targets Gender Pay Gap with Plan to Collect Companies' Salary Data," The Washington Post, (accessed June 7, 2016), [available at https://www.washingtonpost.com/news/wonk/wp/2016/01/29/ obama-targets-gender-pay-gap-with-plan-to-collect-salary-datafrom-big-businesses].

Park, C. Whan, Bernard J. Jaworski, and Deborah J. Maclnnis (1986), "Strategic Brand Concept-Image Management," Journal of Marketing, 50 (October), 135-45.

Pearl, Rebecca L., Rebecca M. Puhl, and Kelly D. Brownell (2012), "Positive Media Portrayals of Obese Persons: Impact on Attitudes and Image Preferences," Health Psychology, 31 (6), 821-29.

Pescosolido, Bernice A., Jack K. Martin, Annie Lang, and Sigrun Olafsdottir (2008), "Rethinking Theoretical Approaches to Stigma: A Framework Integrating Normative Influences on Stigma (FINIS)," Social Science \& Medicine, 67 (3), 431-40. 
Peterson, Robert A. and Alain J. P. Jolibert (1995), "A MetaAnalysis of Country-of-Origin Effects," Journal of International Business Studies, 26 (4), 883-900.

Phelan, Jo C., Bruce G. Link, Ann Stueve, and Bernice A. Pescosolido (2000), "Public Conceptions of Mental Illness in 1950 and 1996: What Is Mental Illness and Is It to Be Feared?" Journal of Health and Social Behavior, 40 (5), 188-207.

Pinker, Steven (2003), The Blank Slate: The Modern Denial of Human Nature. New York: Penguin Books.

Pogash, Carol (2008), "Free Lunch Isn't Cool, So Some Students Go Hungry," The New York Times, (accessed February 16, 2016), [available at http://www.nytimes.com/2008/03/01/education/ 01lunch.html].

Puhl, Rebecca M. and Chelsea A. Heuer (2009), "The Stigma of Obesity: A Review and Update," Obesity, 17 (5), 941-64.

Remedios, Jessica D. and Samantha H. Snyder (2015), "How Women of Color Detect and Respond to Multiple Forms of Prejudice," Sex Roles, 73 (9), 371-83.

Rodriguez Mosquera, Patricia M., Tasmiha Khan, and Arielle Selya (2013), "Coping with the 10th Anniversary of 9/11: Muslim Americans' Sadness, Fear, and Anger," Cognition and Emotion, 27 (5), 932-41.

Ruth, Julie A. (2008), "Third-Party Effects in Servicescape Environments: Insights from Urban Consumers in Apartheid and Post-Apartheid South Africa," in Brick \& Mortar Shopping in the 21st Century, Vol. 11, Tina M. Lowrey, ed. New York: Taylor \& Francis, 197-220.

- and Bernard L. Simonin (2003), “'Brought to You by Brand A and Brand B': Investigating Multiple Sponsors' Influence on Consumers' Attitudes Toward Sponsored Events," Journal of Advertising, 32 (3), 19-30.

Saatçioğlu, Bige and Canan Corus (2016), "An Inclusive Approach to Consumer Vulnerability," in Consumer Vulnerability: Conditions, Contexts and Characteristics, K. Hamilton, S. Dunnett, and M. Piacentini, eds. Abingdon, UK: Routledge, 31-42.

and Julie L. Ozanne (2013), "Moral Habitus and Status Negotiation in a Marginalized Working-Class Neighborhood," Journal of Consumer Research, 40 (4), 692-710.

Sanders, Clinton R. (1988), "Marks of Mischief: Becoming and Being Tattooed," Journal of Contemporary Ethnography, 16 (4), 395-432.

Sandikçi, Özlem and Güliz Ger (2010), "Veiling in Style: How Does a Stigmatized Practice Become Fashionable?" Journal of Consumer Research, 37 (1), 15-36.

Scaraboto, Daiane and Eileen Fischer (2013), "Frustrated Fatshionistas: An Institutional Theory Perspective on Consumer Quests for Greater Choice in Mainstream Markets," Journal of Consumer Research, 39 (6), 1234-57.

Shin, Hyeyoung, John F. Dovidio, and Jaime L. Napier (2013), "Cultural Differences in Targets of Stigmatization Between
Individual- and Group-Oriented Cultures," Basic and Applied Social Psychology, 35 (1), 98-108.

Steinmetz, Katy (2014), "Burger King Debuts Gay Pride Whopper," Time, (accessed February 28, 2016), [available at http://time.com/ 2947156/burger-king-debuts-gay-pride-whopper].

Striley, Katie Margavio (2014), "The Stigma of Excellence and the Dialectic of (Perceived) Superiority and Inferiority: Exploring Intellectually Gifted Adolescents' Experiences of Stigma," Communication Studies, 65 (2), 139-53.

Swank, Eric, Breanne Fahs, and David M. Frost (2013), "Region, Social Identities, and Disclosure Practices as Predictors of Heterosexist Discrimination Against Sexual Minorities in the United States," Sociological Inquiry, 83 (2), 238-58.

Tajfel, Henri (1981), Human Groups and Social Categories: Studies in Social Psychology. Cambridge, UK: Cambridge University Press.

Thomas, Jane Boyd and Cara Peters (2015), "Lululemon Athletica and a Series of Bad Marketing Decisions," Journal of Critical Incidents, 8, 102-05.

Van Gils, Wouter and Gerbert Kraaykamp (2008), "The Emergence of Dual-Earner Couples: A Longitudinal Study of the Netherlands," International Sociology, 23 (3), 345-66.

Van Laar, Colette, Belle Derks, Naomi Ellemers, and Dennis Bleeker (2010), "Valuing Social Identity: Consequences for Motivation and Performance in Low-Status Groups," Journal of Social Issues, 66 (3), 602-17.

Wooten, David B. (2006), "From Labeling Possessions to Possessing Labels: Ridicule and Socialization Among Adolescents," Journal of Consumer Research, 33 (2), 188-98.

Yang, Lawrence Hsin, Arthur Kleinman, Bruce G. Link, Jo C. Phelan, Sing Lee, and Byron Good (2007), "Culture and Stigma: Adding Moral Experience to Stigma Theory," Social Science \& Medicine, 64 (7), 1524-35.

Yeh, Marie A., Robert D. Jewell, and Michael Y. Hu (2013), "Stereotype Processing's Effect on the Impact of the Myth/Fact Message Format and the Role of Personal Relevance," Psychology and Marketing, 30 (1), 36-45.

Yue, Lori Qingyuan, Hayagreeva Rao, and Paul Ingram (2013), "Information Spillovers from Protests Against Corporations: A Tale of Walmart and Target," Administrative Science Quarterly, 58 (4), 669-701.

Zielinski, Alex (2016), "The CDC Has Some Insulting Advice for Women Who Drink," (accessed February 21, 2016), [available at http://thinkprogress.org/health/2016/02/03/3745802/cdc-victimblaming].

Zitek, Emily M. and Michelle R. Hebl (2007), "The Role of Social Norm Clarity in the Influenced Expression of Prejudice over Time," Journal of Experimental Social Psychology, 43 (6), 867-76. 